\title{
Developing an Model for Development of Technology \& Engineering-centered integrative education program in STEM/STEAM field
}

\author{
S. Kim ${ }^{1}$ \\ ${ }^{1}$ Department of Technology education, Woonam middle school, Osan, CO 18151, Korea
}

\begin{abstract}
Background/Objectives: The purpose of this study is to develop a model for developing integrated education programs centered on technology and engineering at STEM/STEM fields in elementary, middle and high schools. Methods/Statistical analysis: We explored ways to integrate the various knowledge of the subject that students learned in class to solve the problem when they encountered technological and engineering problems that occurred in real-world. It also developed an integrated education model that is based on the development of integrated education programs centered on the areas of technology and engineering. Findings: The results of the study make it easier for teachers to develop integrated education programs centered on technology and engineering. This research also has significant value because the hands-on activities in STEM/STEM field are mostly about technology and engineering. This research also has significant value because the hands-on activities in STEM/STEM field are mostly about technology and engineering. Improvements/Applications: This will foster high-level thinking skills such as the ability to integrate the divided forms of knowledge learned from each of the subjects oriented in technology and engineering education, the ability to solve problems, the ability to cooperate, the ability to communicate and decide, and creativity.
\end{abstract}

\section{Index Terms}

integrated education, technology and engineering education, technology and engineering education centered integrated education, STEM/STEAM

\footnotetext{
Corresponding author : S. Kim

ksys21@korea.kr

- Manuscript received November 28, 2018

- Revised December 12, 2018 ; Accepted December 14, 2018.

- Date of publication December 31, 2018.

(c) The Academic Society of Convergence Science Inc.

2546-1583 $\odot 2017$ IJEMR. Personal use is permitted, but republication/redistribution requires IJEMR permission.
} 


\section{INTRODUCTION}

Yi[1] defined education as an act of teaching the knowledge, attitudes and functions needed in the future era when students will live. Mark Benioff, president of Sales Force, a leading global company in Silicon Valley, said, "If we want to succeed in the fourth industrial revolution, we will eventually start and end education."

What is the knowledge, attitude and function that our students need ahead of the Fourth Industrial Revolution?

The UK has recently revised the changes in design and technology to match innovation and the digital industry and explained that students will learn 3D printing or robots in schools[2,3]. In addition, through the recently revised curriculum, Korea has included cutting-edge technologies such as 3D printing, drones, robots and big data as learning elements[4]. France, remembered as a country of art and fashion, is turning into a good country to start a fourth industrial revolution in artificial intelligence, machine learning and big data thanks to various policies leading innovation and research for the future, based on technology and engineering education in lower secondary schools, technical creation and innovation education in upper secondary schools and solid engineering education in universities[5,6]. Germany is traditionally a country with systematic vocational education and has a very solid position in technology-related jobs[7,8]. Unlike Obama, President Trump, who had continued passive policies such as cutting the budget for STEM education and deleting related programs, is also drawing up a turning point in his policies on STEM education $[9,10]$.

As such, many countries around the world are pursuing various changes in technology/Engineering education, As such, many countries around the world are pursuing various changes in technology/Engineering education, but ' $\mathrm{T}$ ' meaning technology and 'E' meaning engineering have not been noticed in integrated education[11-12]. However, the new learning standards and technology $\&$ engineering-based hands-on activities are gaining attention as they are being announced continuously[13-14]. Through STEM/STEAM education, technology and engineering have begun to draw attention from education for students because problem-solving skills, one of the necessary abilities for our students to live in the era of the Fourth Industrial Revolution, must be capable of integrating various knowledge. Thus, the importance of integrated education for fostering future talent continues to be mentioned, and technology and engineering are located at the center of integrated education needed for our students who will live in the era of the Fourth Industrial Revolution. However, in order to provide integrated education within technical education, many technical teachers find it difficult to integrate education in technical classes because they need to re-educate each STEM/STEM subject area and know the best way to apply each subject area during planning and teaching.[15]. STEM/STEAM training using technical training content has been designed as a pilot project until now, but it has not been planned as a whole curriculum[16]. Methodological papers on how integrated STEM/STEAM education can be applied to technical and engineering education programs are published in such journals as Technology and Engineering Teacher and Children' Technology and Engineering. Several teachers and some organizations and education ministries have also developed educational materials to help teachers guide from the STEM/STEAM perspective. However, not only are many teachers unaware of existing STEM/STEAM efforts, but they often do not know what contribution students must make to learn and understand STEM/STEAM courses. Therefore, systematic research on what concepts integrated education has in technology and engineering education and how programs for integrated education should be developed is necessary. The aim is to develop a concept of integrated education centered on technology and engineering, and a model to develop integrated education programs centered on technology and engineering, so that our students who will live in the future can develop the knowledge, attitudes and functions needed in the era in which they live. The study will show how technology and engineering subjects are integrated in integrated classes such as STEM or STEAM, and how teachers develop a technology and engineering-centered integrated STEM/STEAM program.

\section{AN CONCEPT OF TECHNOLOGY \& ENGINEERING-CENTERED INTEGRATIVE EDUCATION PROGRAM}

STEAM education is a form of education covering not only STEM education, but also science, technology, engineering, math and so on. The students say that technology \& engineering education is most associated with a ' robot' themecentered education activities[17-19], and technology $\&$ engineering teachers should be in full charge of this subject once robot is included in regular courses of study.

Through educational activities about robot, serving as part of technology \& engineering education, 
students empathize with the fact that the importance of the subject 'technology', 'technology \& engineering' is very heavy. Thus, considering that Integrative STEM from technology \& engineering education, integrated education like STEAM education need to be redefined based on technology $\&$ engineering education.

Technology \& engineering is so closely related to the real world that there is no field unrelated to technology \& engineering, and integration of technology \& engineering happens in the real world. Thus, every education al activities based on realworld on technology \& engineering could be integrated activities based on technology \& engineering. The "figure 1" is to explain integrated education based on technology \& engineering education.

There is a person cooking Bibimbap. In Bibimbap, a lot of kinds of ingredients such as rice, the main ingredient, vegetables, stir-fried beef, eggs, red pepper paste, and sesame oil are included. The cook chooses fresh ingredients to make the taste better, cleans and cooks them. We enjoy Bibimbap, and the ingredients are well mixed, thereby providing us with nutrients. The researcher is about to explain integrated education based on technology \& engineering by alluding to Bibimbap, one of the traditional Korean dishes.

Rice, the main ingredient for Bibimbap can be likened to technology \& engineering, which is the center for integrated education. Other related subjects for integrated education based on Technology \& Engineering education including science, mathematics, and other subjects are other kinds of ingredients, the cook can be likened to a technology \& engineering teacher, and finally the customer can be likened to students. As the cook carefully chooses every ingredient to make the taste better, the technology \& engineering teacher tries to harmonize factors after selecting integrated factors to elevate the quality of integrated education. Also, students can develop various capabilities through educational activities as customers have a very good diet.

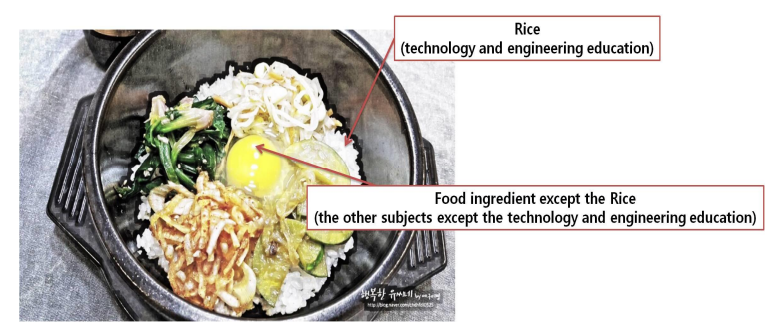

Fig. 1. “TE(Technology \& Engineering)"_Bibimbap explaining integrated education based on Technology \& Engineering.

Also, technology and engineering teacher, which can be likened to a cook making Bibimbap, also can be compared to a captain of high speed trains(figure 2). Technology and engineering teachers lead education programs to let students have abilities as people who will lead the future like creativity, problem-solving abilities, and communication skills. As captains of high speed trains carry passengers to the destinations safely and fast, technology \& engineering teachers should make students reach the instructional goal without being flustered. In other words, overall context of classes are constructed by technology \& engineering teachers, and they guide content factors like engineering, math, science or other kinds of subjects to the goal that Technology \& Engineering education pursues

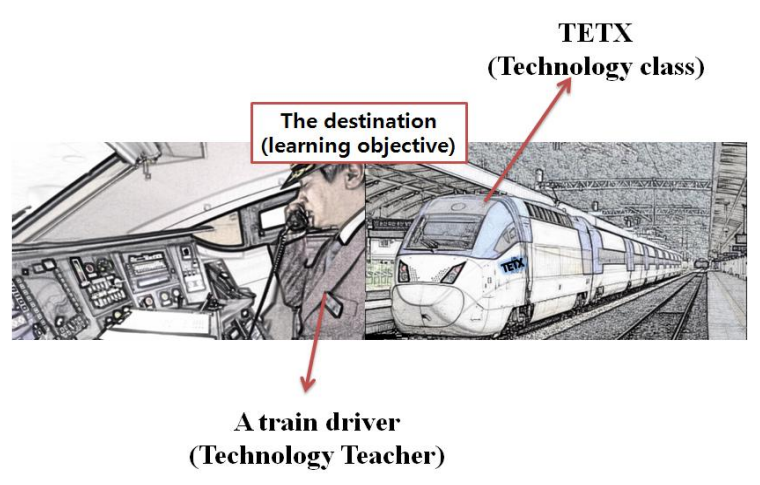

Fig. 2. "TETX(Technology and Engineering Train eXpress)" is high speed railroad for integrated education based on Technology \& Engineering education

Based on such notions, the figure above displays concept models for integrated education based on Technology \& Engineering like "figure 3".

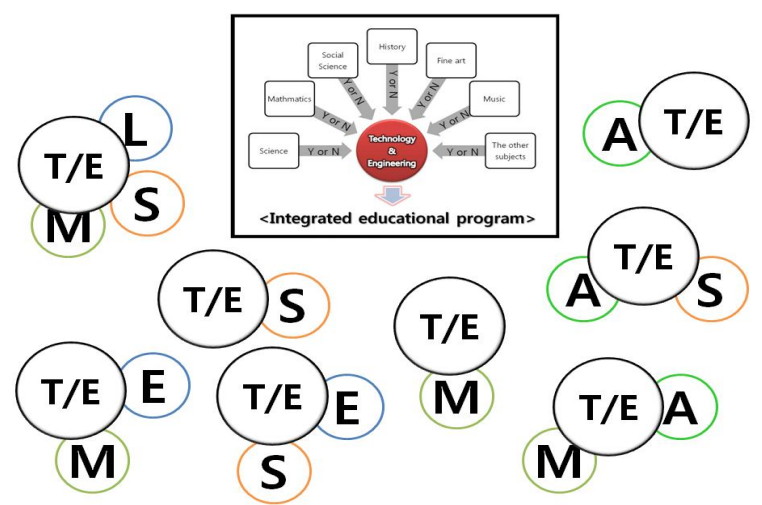

Fig. 3. It is a Concept model for the integrated education based on Technology \& Engineering in STEM/STEAM field.

The new trends of recent integrated education improves study and induces connection of subject with one another by including Technology \& Engineering, math, science and every kind of subject. Also, the integrated subject will be different each. This is because it is integrating subject depending on activities or topics, not cases for integrating all subjects. Thus, Yes or No is included in this concept 
model. At this moment, since Technology \& Engineering teachers make classes, the content of Technology \& Engineering subject must be included, and other subjects like math, engineering, science and so on might be included depending on whether it is appropriate based on activities and/or topics. Once integrated subjects are decided and integrated content factors are choses, it will be applied in classes based on the content of Technology \& Engineering subject.

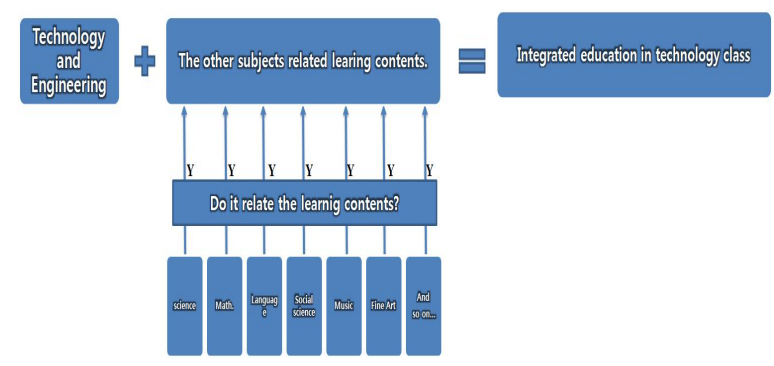

Fig. 4. It is a Specification of Concept model for the integrated education based on Technology \& Engineering in STEM/STEAM field.

\section{AN Model FOR DEVELOPMENT OF TECHNOLOGY \& ENGINEERING-CENTERED INTEGRATIVE EDUCATION PROGRAM}

When Technology \& Engineering teachers prepare classes by preparing integrated education based on Technology \& Engineering, they develop new educational programs or restructure existing ones. At this moment, procedure models for restructure or developing programs are necessary.

Procedure models consist of preparation, development and evaluation[19], and revision or complement would be performed depending on results of evaluation stages.

First of all, in preparation stage, the needs of education, we analyze need of education fields and select integrated types. When selecting integrated types, I used coordinate models for analysis of integrated models from Kim[19], which complemented integrated type analysis model of Lee[20] based on the contents of mathematics education. This explains integrated types explained in 3 axes, $\mathrm{x}, \mathrm{y}$, and $\mathrm{z}$-axis as coordinates comprehendible with mathematical thinking[19]. It was revised because the existing models are applied differently from what we have learnt in textbooks, which might cause difficulty in integrated thinking or utilize it in real-lives. In fact, coordinates would be more appropriate to understand 3-D because we explain $\mathrm{x}, \mathrm{y}$ and $\mathrm{z}$-axis in coordinates. Once integrated types are chosen, we can decide whether to choose learning type centered on theme or activities. Also, we can deduce standards for selecting tasks.
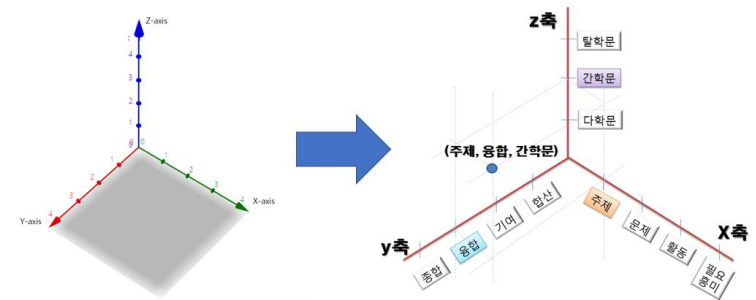

Fig. 5. It is a Coordinate model for integrated type analysis[19].

In the development stage, we choose learning task based on standards, set up educational goals, and extract contents of study based on curriculum. At this moment it is important that we decide integrated factors by selecting teacher except those in charge of Technology \& Engineering as expert group and argue with them. We decide integrated factor through theme network if theme centered, and webbing if activity centered, and organize content of study based on Technology \& Engineering education. We organize the content of study based on contents of Technology \& Engineering education. We organize the contents following the contents of classes.

In evaluation step, we conduct validity check through a group of experts in the field of integrated education who contributed to development of educational programs, and conduct pilot-test and field-test. Once the evaluation by expert groups and students is over, the final integrated educational program is over after reflecting suggestions and complementing and revising them.

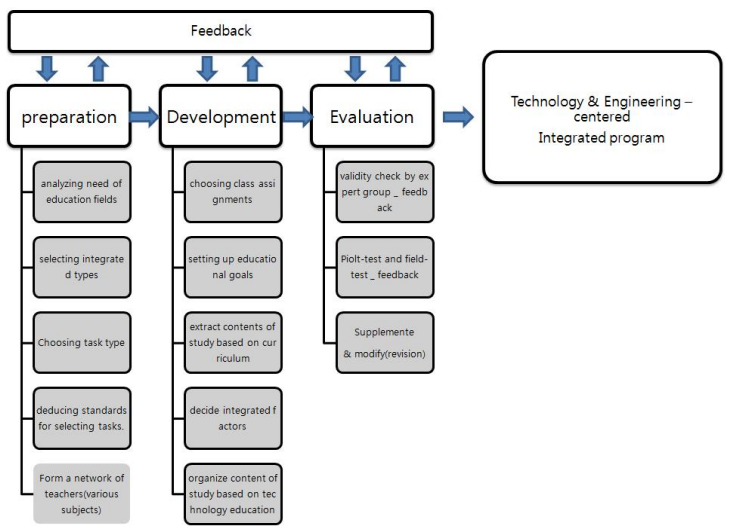

Fig. 6. The process model for developing of technology \& engineering - centered integrative educational program.

If new integrated programs is already qualified and used for classes, it is reorganized based on integrated education. At this moment, the standard stage omitted, and the step for choosing tasks in development step is omitted. Also, since existing educational programs are usually utilized to apply them to the field, a lot of classes usually have both 
preliminary and field examinations. In today`s field, usually the same program is applied to several classes, so evaluation step is also included in this step. Finally, procedure stop can be used flexibly for the field because it is usually used for revision and complement for preparation of the upcoming year.

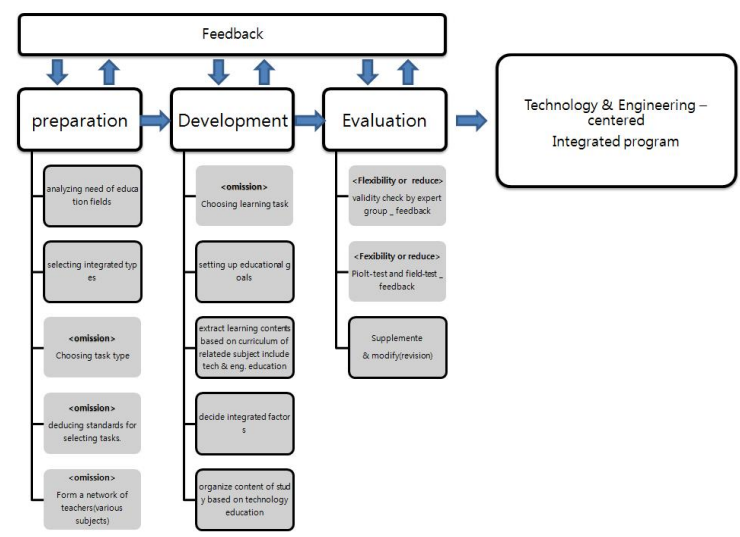

Fig. 7. This process model was reorganized on the basis of the previously developed integrated program

In development step, we develop a guidance plan, student activities paper, evaluation rubric to utilize them in class when composing contents for integrated education. The procedure of class is preparation, implementation, and closure. Also integrated education based on Technology \& Engineering education is usually hands-on activity. At this moment, implication is achieved by the step of problem recognition, research and development, implimentation and evaluation step.

When organizing student activities paper, it should be easy to look into contents by inserting QR codes. Also, indicating how educational contents are related to other subjects are also informative for students or class work studies or teachers.

Also, integrated factors chosen by theology teachers might comprise a large part of class depending on activities or topics or vice versa. For instance, in classes publishing newspapers or magazines on future technologies or pro-con debate classes, factors related to languages will be more prevalent. Also, in classes focusing on bio-technology(bio-engineering), contents related to science (biology) will be more prevalent.

Integrated classes are taught with Technology \& Engineering subject as the center, so the part that Technology \& Engineering accounts for would be high. Also, in activities leading to patent applications by invention or development of products, the part that engineering accounts for will be higher, because optimizing products is necessary. Thus, once integrated ratios are indicated on teachers' manuals or student activities sheets, it will allow teachers study related part in detail and students to get to know that the activities are also related to other subjects. In fact, students said as follows after class with contents on integrated factors were indicated on student activities sheet was over.

student A : I thought of the content that I learned in technology \& engineering class while construing moving toys. I complained that I do now know why I learn such hard notions while learning notions on elements of machine. When discussing ideas with peers, we had problems with gap between axes, and we could think of utilization of belts, pulleys, and chains. If we had not learned them in technology \& engineering classes, we would have failed to find solutions. Also, it made me decide to take technology \& engineering class harder.

student B :It was the moment when we were making a reading desk through use of robots. Science class was usually boring. However, when I was agonizing about what method I should use to control velocity of motor, my technology teacher told me not to increase speed of the motor, since quantity of motion depends on velocity and the fluctuation in the quantity of motion is impulse. Based on what the teacher said, I could make the robot move more smoothly. Though I thought why I learn such boring notion in science class, I got to realized that it was necessary to make the robot that I like, and it was a chance for me to focus on science class. I am now taking science class harder than any other peers.

student C : I designed space exploiting stairs. However, since I had to make it as a model, I was forced to calculate figures. In the activity sheet, there was some space for calculation using proportional expression and deciding reduction ratio. In fact, I really hate math. People say if I can calculate money, I do not need to study math more and I agree with them. Also, I love technology \& engineering class, because I can make what I want based on my thinking and I have activities in person unlike other subjects. However, I have never thought that I need to use mathematic notion in technology \& engineering class. Because of my experience, I got to think that I need to study mathematics.

Like so, students`attitudes to subjects has a 180degree turnaround by indicating that activities are relevant to subjects. Also, by indicating integrated factors on materials for teachers, it makes teachers study the class in detail and enables them to ask other teachers for advice. Also, since importance in indicted, it could be a guideline for deciding importance of class work study. In fact, teachers attended class activities say as follows.

Teacher A : Through indication on integrated factors included in student activities sheets, it was very 
impressive that students can get to know subjects are integrated with each other. Also, it made me study more with interests by indicating part that I can mention with my schema.

Teacher B : Because of integrated factors, I am sometimes confused with how in detail I should study teaching. However, since the importance is easily visible, I can guess what part should be more empathized. Also, I can study teaching more systemically be asking teachers in charge of other subjects while studying teaching.

Teacher C : It served as a good guideline for team teaching. Since integrated sections were indicated and I browsed another textbook of other subjects, the activity that I planned was in May, but students learn it next semester. Thus, I reorganized course of study with a teacher in charge of computer. Through this chance, I could get to exchange various materials for class, and get closer.

The figure shows integrated factors by Technology \& Engineering teachers in class depending on importance. If the Technology \& Engineering subject is 100 , each importance can be indicated. The importance can be indicated like very large, large, regular, small, and very small, and we can grasp the importance of part through images. However, is could be subjective because the importance is indicated by Technology \& Engineering teachers. It is important that they induce appropriate impotence of integrated factors through discussion among teachers.

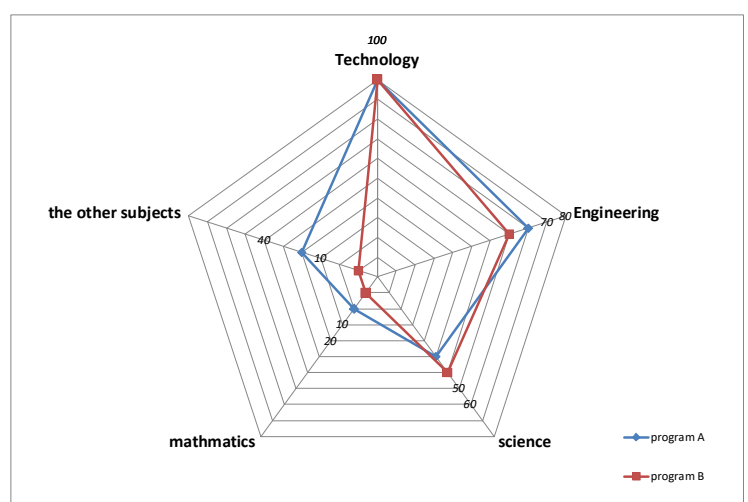

Fig. 8. The graph indicating extents of integration of educational programs (schematization of degree of integration rates).

Korean integrated education is called STEAM education or convergent human resource education. In Korean STEAM, Technology \& Engineering, engineering, math or other subjects are mixed with science education. However, in the field, many educational activities are performed in Technology \& Engineering classes, so Technology \& Engineering teachers STEAM should be based on
Technology \& Engineering education. As a result, Kim[17] utilized it in gifted and talented education by suggesting integrated education based on Technology \& Engineering education called TEAMS education which is a changed name of STEAM, considering collaboration class is being done.

The integrated education suggested in this research, this can be the basic model as integrated education based on Technology \& Engineering teachers and contents.

\section{Conclusion}

Not only Technology \& Engineering education is related to our real life and but also other subjects. Thus, Technology \& Engineering subject is very relevant to integrated education. We cannot deny the fact that we are enjoying convenience thanks to integration of many fields. In segmented curriculum, by thinking that it is hard to apply the education to this integrated real life, STEM or STEAM education is being tried in many countries like Korea. In regular curriculum, after-school education and experience activity, many kinds of integrated education is being done, and this research studies how integrated education can be done based Technology \& Engineering subject and suggested the Technology \& Engineering educational model, materializing the notion of STEAM education based on Technology \& Engineering subject.

Through this, technology and engineering teachers can prepare theme or activity centered educational programs based on other subject, which allows them to search relevance to other subject and make communities with other subjects. Additionally, through integrated education based on Technology \& Engineering education, it not only can it arouse interests in Technology \& Engineering education but also raise its image.

\section{REFERENCES}

[1] Yi, S. (2001). The Challenges and Improvement Direction of Technical Education in Response to Knowledge-Based Society. The Korean Journal of Technology Education, 1(1), 15-29.

[2] Department for Education in England. (2014). The national curriculum in England Framework document.

[3] BBC NEWS. (2014). How is the national curriculum changing. Retrieved from https://www.bbc.com/news/education-28989714

[4] Department of Education in KOREA. (2015). 2015 Revised national curriculum.

[5] Ministère de l'Éducation nationale. (2019). Développer les compétences numériques des élèves. Retrieved from https://www.education.gouv.fr/cid133192/le-numeriqueservice-ecole-confiance.html

[6] Insititute for Information \& communications Technology Promotion. (2018). Global ICT R\&D Policy Trends : Policy Trends for the Training of Human Resources to Respond to the Fourth Industrial Revolution in Major Foreign Countries. 
[7] Bundesministerium für Bildung und Forschung. (2018). Hightech-Strategie 2025. Retrieved from https://www.bmbf.de/de/die-neue-hightech-strategie-86.html

[8] Kang, H. K., Kwan, S. J. \& Lee, Y. J. (2013). Current Status and Implications of Job Training System in Germany. Global Market Report 13-020, Korea Trade Investment Promotion Agency.

[9] Korean Institute of S\&T Evaluation and Planning. (2019). Science, ICT Policy and Technology Trends, 134. 15-16.

[10] THE WHITE HOUSE. (2018). CHARTING A COURSE FOR SUCCESS: AMERICA'S STRATEGY FOR STEM EDUCATION.

[11] Elizabeth. A. P. (2015). The "E" in STEM: Explicitly Teaching Engineering. Retrieved from https://www.advanced.org/source/e-stem-explicitly-teaching-engineering.

[12] Bill, R. P. (2017). Is The "T" In STEM Supposed To Be Silent?. Retrieved from https://www.huffpost.com/entry/isthe-t-in-stem-supposed b 12324700 .

[13] Barron, A. E., Kemker, K., Harmes, C. \& Kalaydjian, K. (2003). Large-scale research study on technology in K-12 schools: Technology integration as it relates to the National Technology Standards. Journal of Research on Technology in Education, 35(4), 489-507.

[14] International Society for Technology in Education. (2007). National educational technology standards for students.

[15] Banks, F. \& Barlex, D. (2014). Teaching STEM in the secondary school: Helping teachers meet the challenge. Routledge.

[16] Becker, K. \& Park, K. (2011). Effects of integrative approaches among science, technology, engineering, and mathematics (STEM) subjects on students' learning: A preliminary meta-analysis. Journal of STEM Education: Innovations \& Research, 12(5/6), 23-37

[17] Kim, S. A. \& Jee, S. D. (2006). A Survey on Teacher's Cognition for the Improvement of Robotics Education in Public Education. Journal of Korea robotics society, 6(4), 365-372.

[18] Kim, S. \& Yi, S. (2015). Comparison of Perception Towards the STEAM Education for Mathematics/Science-Gifted Students and Invention-Gifted Students. Journal of LearnerCentered CurricuIum and Instruction, 15(12), 1029-1049.

[19] Kim, S. (2015). The developments of TEAMS integrative educational programs based on 'robot' theme-centered for the gifted education in secondary school. Ph.D. dissertation, Korea National University of Education, Cheongju, CB, 2005, unpublished

[20] LEE, S. G. (2001). (The) Development of technology education program based on theme-centered integrative approach. Ph.D. dissertation, Korea National University of Education, Cheongju, CB, 2001, unpublished 